\title{
NUTRIÇÃO MINERAL DE ESPÉCIES DO CERRADO I. Composição Química de Byrsonima coccolobifolia (Sp) Kunth e Kielmeyera coriacea (Sp) Mart.
}

\author{
H. E. Martinez $* *$ \\ R. A. Pitelli *** \\ H. P. Haag ****
}

\section{RESUMO}

Com a finalidade de se determinar a concentração e extração dos macro e micronutrientes, assim como o teor de alumínio, em espécies que vegetam em condições de Cerrado, foram coletadas amostras de Byrsonima coccolobifolia (Sp) Kunth em um Regosolo nos meses de janeiro, agosto e novembro na região de Cajurú no Estado de São Paulo, Brasil.

No mês de janeiro foram coletadas em igualdade de condições amostras de Kilmeyer coriacea (Sp) Mart. e "Samambaia".

Os resultados mostram que:

1 - A estação climática do ano não tem influência marcante nas especies;

2 - A concentração dos macro e micronutrientes, salvo algumas exceções, é semelhante a das plantas cultivadas;

3 - O xilopódio é órgão armazenador de nutrientes na espécie "samambaia";

4 - As espécies não são acumuladoras de alumínio.

\section{INTRODUÇÃO}

A região dos Cerrados ocupa aproximadamente 180 milhões de hectares estendendo-se pela região centro-oeste, atingindo parte das regiões norte, nordeste e sudeste do país .

A divulgação dos estudos sôbre Cerrados sucedem-se desde 1956 através de reuniões científicas. Assim, o $1^{\circ}$ Simpósio teve lugar na Universidade de São Paulo em 1962. Decorridos três anos realizou-se

* Entregue para publicação em: 19-12-1977.

* E.S.A. "Luiz de Queiroz", USP, Piracicaba, SP.

*** Faculdade de Ciências Agrárias e Veterinárias de Jaboticabal, SP.

**** E.S.A. "Luiz de Queiroz", USP, Piracicaba, SP. 
o 2. ${ }^{\circ}$ Simpósio no Rio de Janeiro em 1965 na sede da Academia Brasileira de Ciências. Em 1971 o Departamento de Botânica da Universidade de São Paulo foi sede do 3. ${ }^{\circ}$ Simpósio e em Brasília no ano de 1976 teve lugar o 4. ${ }^{\circ}$ Simpósio.

De todos os Simpósios, somente no $2^{\circ}$, LABOURIAU (1966) enfatizou a necessidade de estudos da nutrição mineral das plantas nativas dos Cerrados, afirmando "um dos aspectos inexplorados da ecologia das plantas de Cerrado está na sua nutrição mineral".

GOTTLIEB, et alii (1966), afirmaram que as espécies de Cerrado já foram submetidas a um processo de seleção e possuem, portanto, mecanismas de composição de deficiências que importa descobrir, pois representam "soluções da evolução vegetal no Cerrado. Afirmam, ainda os autores "Do ponto de vista tecnológico o conhecimento de tais mecanismos pode contribuir para selecionar plantas mais adequados à cultura no Cerrado, por exigirem modificações menos drásticas do meio em que se pretende cultiva-las com rendimento econômico".

Recentemente, em 1976, a "EMBRAPA (1)" lançou uma bibliografia analítica incluindo trabalhos de caráter científico em número de 766 .

Para atestar a escassez de trabalhos sôbre a nutrição de plantas nativas a referida obra apresenta tão somente quatro referências.

MEDTSCH (1966), determinou teores de $P$ em pares de espécies vicariantes, uma de cerrado e outra de mato, e em pares de espécies do mesmo gênero, mas sem afinidade. Verificou que, nas espécies vicariantes o $\mathrm{P}$ apresenta concentração comparável indicando parentesco. $O$ fato de viver em solo pobre em $P$ não impede que tais plantas obtenham e armazenem o nutriente tanto quanto o fazem suas "irmãs" silvestres. Conclui o autor que os vegetais do cerrado ao se adaptarem a baixos níveis nutricionais, conseguindo preservar em solos mais pobres, as características químicas que vigoram nas espécies florestais.

MEDITSH (1966), analisou $\mathrm{B}, \mathrm{Ca}, \mathrm{K}, \mathrm{Na}, \mathrm{Zn}$ e $\mathrm{Al}$ nas folhas de 19 espécies comuns nos Cerrados e verificou que o $\mathrm{K}, \mathrm{Ca}$ e $\mathrm{Na}$ tendem a se acumular na nervura; B e Zn concentram-se no limbo. A concentração de Al tanto pode ser elevada no limbo como na nervura.

GOODLAND (1971), analisou os efeitos dos altos teores de $\mathrm{Al}$ solúvel encontrados nos solos sob vegetação de Cerrado, afirmando que todas as plantas do Cerrado desenvolveram uma tolerância ao Al. Um entendimento do mecanismo pelo qual as plantas do Cerrado podem extrair os nutrientes do solo, apesar da presença do $\mathrm{Al}$, tornar-se-ia muito útil à agronomia, no dizer do autor.

O presente trabalho teve por objetivo:

- Aquilatar a concentração dos macro e micronutrientes e alumínio em duas espécies de Cerrado, influenciadas pelas estações climáticas do ano.

(1) Empresa Brasileira de Pesquisa Agropecuária - Brasília, Brasil. 


\section{MATERIAL E MÉTODOS}

Plantas jovens de Byrsonima coccolobifolia (Sp) Kunth e Kielmeyera coriacea Mart foram coletadas em um Regosolo situado no município de Cajurú no Estado de São Paulo. Exemplares da primeira espécie foram coletadas em agosto, novembro e janeiro, sendo que da segunda foram coletadas somente no mês de janeiro. Foram colețadas ainda, na mesma época plantas denominadas "samambaias".

As plantas coletadas foram preparadas e analisadas para $\mathbf{N}, \mathbf{P}, \mathrm{K}$, $\mathrm{Ca}, \mathrm{Mg}, \mathrm{S}, \mathrm{B}, \mathrm{Cu}, \mathrm{Fe}, \mathrm{Mn}, \mathrm{Mo}$ e $\mathrm{Al}$ de acordo com os métodos descritos em SARRUGE e HAAG (1974).

\section{RESULTADOS E DISCUSSÃO}

As plantas provenientes do solo e clima Regosolo cujas características gerais segundo a COMISSÃO DE SOLOS (1960) são: Caracteriza-se por ser um solo profundo, muito friável, de textura muito leve, acentuadamente drenado.

Normalmente ácido e com fertilidade aparente muito baixa. Capacidade de permuta de cations (T) varia no horizonte $A$ de 0,86 a $4,34 \mathrm{~m} \mathrm{eq} / 100 \mathrm{~g}$ de solo. A saturação de bases (V) no horizonte A varia de 13,8 a $30,2 \%$. Os valores de $\mathrm{pH}$ em água apresentam-se entre 4,6 a 5,5. Os solos desta unidade são extremamente pobres em $\mathrm{Ca}, \mathrm{Mg}$, $\mathrm{K}$ e Na; sendo considerados os mais pobres do Estado nestes elementos".

Ainda de acordo com a COMISSÃO DE SOLOS (1960), o Município de Cajurú, encontra-se no tipo climático $\mathrm{Aw}$ com índice pluviométrico variando entre 1100 e $1300 \mathrm{~mm}$ com estação seca de maio a setembro.

De acôrdo com BLANCO \& GODOY (1967), há uma probabilidade de 68,3\% que a pluviosidade da região apresenta os seguintes índices: janeiro $225 \mathrm{~mm}$; agosto $10 \mathrm{~mm}$; novembro $150 \mathrm{~mm}$. A distribuição da energia solar para a região próxima a Ribeirão Preto apresenta os seguintes valores médios de $Q$ em $\mathrm{cal} / \mathrm{cm}^{2} /$ dia: novembro 556 ; janeiro 510 e agosto 413 segundo CERVELLINI \& SALATI em 1966.

\section{Espécies do Cerrado}

As espécies coletadas são descritas por FERRI (1960) do modo que se segue:

Byrsonima coccolobifolia H.B.K. Arbustos ou árvores atingindo cêrca de 4 metros, tronco muitas vêzes torto, ramificado de casca aspera, folhas opostas, glabras, quase sésseis, oval oblongas ou obovadas, com ápice ora emarginado ora apiculado; superfície lisa, mais escura no 
lado superior, nervuras por vêzes rosadas, nas folhas novas também os bordos são avermelhados, flores albo-rosadas, fruto drupa em cajú base persistem as glândulas do cálice, nome vulgar Muria .

Kielmeyera coriacea Mart. árvores de grande porte, raramente arbustos, ramos tortuosos, sempre glabras de casca suberosa, espêssa e leve que se desprega facilmente; nos ramos se notam com frequência cicatrizes deixadas por folhas ou ramos secundários afastados; folhas alternadas, coriáceas, reunidas nos ápices dos ramos, sub-sésseis, obovadas, de base cuneiforme, opacas, percorridas por nervura mediana larguissima peninervas, latex abundante, panículas contraídas, tomentoso-ferrugíneas de poucas flores grandes, albo-rosadas, sementes muito numerosas, providas de grandes alas, nome vulgar Pau-santo.

Crescimento das Plantas

O crescimento das plantas expressos em produção de matéria seca acha-se assinalado no quadro 1 .

QUADRO 1 - Pêso da matéria sêca $(\mathrm{g})$ das diversas partes de Byrsonimá coccolobifolia. Média de 4 repetições.

\begin{tabular}{|c|c|c|c|}
\hline Parte da olanta & $\begin{array}{c}\text { Agosto } \\
\text { (inverno) }\end{array}$ & $\begin{array}{r}\text { Novembro } \\
\text { (primavera) }\end{array}$ & $\begin{array}{l}\text { Janeiro } \\
\text { (verão) }\end{array}$ \\
\hline & $\mathrm{g}$ & $\mathrm{g}$ & $\mathrm{g}$ \\
\hline Folhas & 101,3 & 24,7 & 80,4 \\
\hline Caule & 351,8 & 24,3 & 122,0 \\
\hline Xilopódio & 108,0 & 158,7 & 71,5 \\
\hline Raízes & 381,6 & 233,4 & 172.2 \\
\hline Total & 561,1 & 207,7 & 273,9 \\
\hline
\end{tabular}

Observa-se que apesar da precipitação pluviométrica mais baixa e valor $\mathbf{Q}$ inferior as duas outras épocas um aumento sensivel no pêso da matéria seca, especialmente nas folhas e no caule no mês de agosto.

\section{Composição química de Byrsonima Coccolobifolia (Sp) Kunth}

A composição porcentual e a extração dos macronutrientes, expressos em função da matéria seca, nas três épocas, acha-se assinaladas no quadro 2.

Nota-se inicialmente que os teores em $\mathrm{N}, \mathrm{K}$ e $\mathrm{Mg}$ nas folhas aumentaram de agosto a janeiro. $\mathrm{O}$ teor de $\mathrm{P}$ aumentou de agosto a novembro, para novamente cair em janeiro. Os teores de $\mathrm{K}$ e $\mathrm{Mg}$ aumentaram nas folhas da estação do inverno para o verão, sendo que o teor de Ca se manteve aproximadamente constante durante o ano. 
Chama atenção a concentração elevada em Ca na espécie de Cerrado. O fato deve estar relacionado ao aprofundamento do sistema radicular até atingir o lençol freático. Assim, RANZANI* (1977) afirmava ter encontrado raízes a profundidade acima de $10 \mathrm{~m}$, localizados junto ao lençol freático cujo índice de pH era superior a 7,0 na região de Pirassununga, SP.

GOTTLIEB et alii (1966), encontraram valores elevados em Ca QUADRO 2 - Porcentagem e extração $(\mathrm{g})$ dos macronutrientes pelas diversas partes da planta em função de épocas. Média 4 repetições.

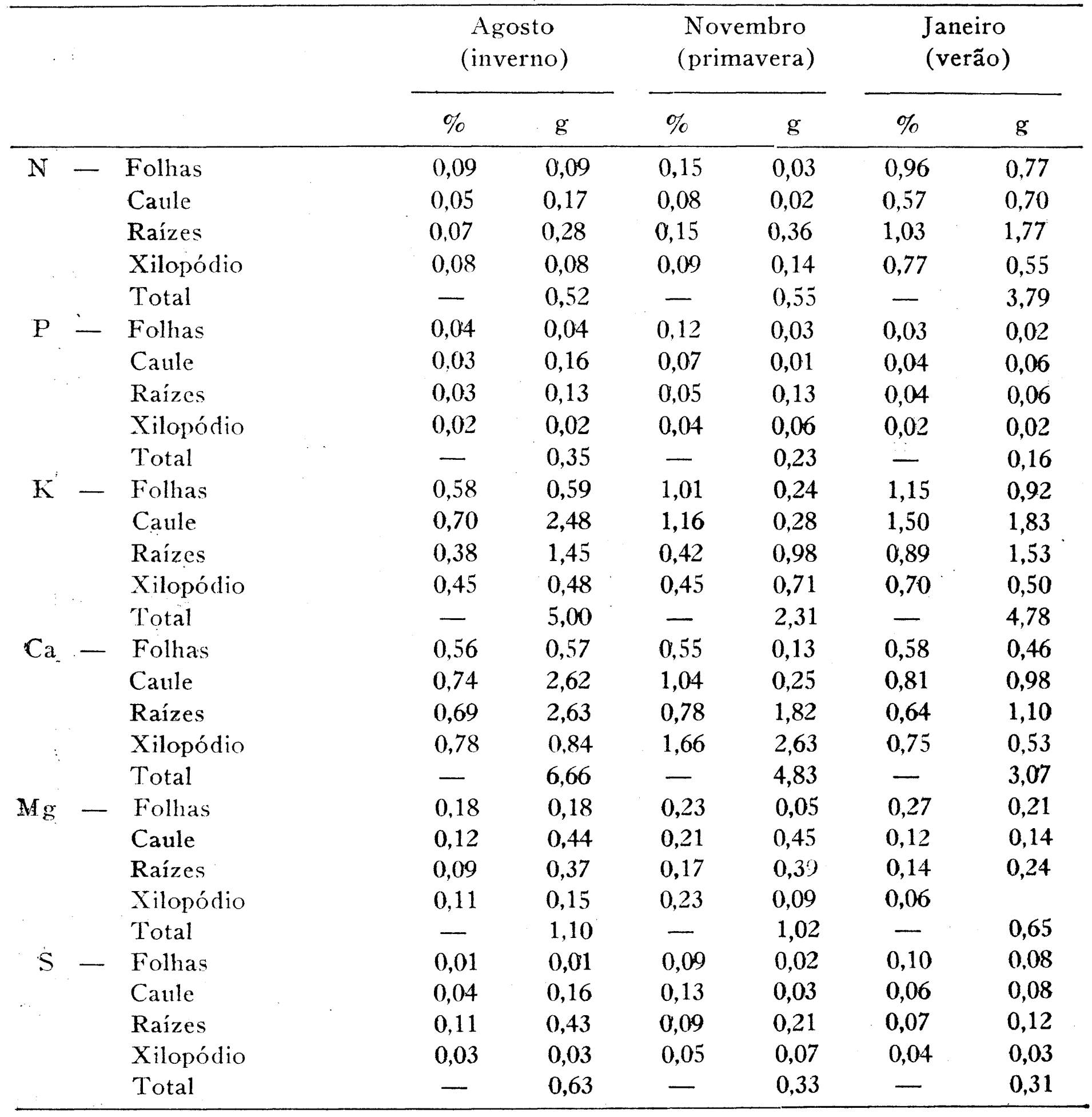

- RANZANI, G. (1977) - Departamento de Solos, Geologia e Fertilizantes, E.A.S. "Luiz de Queiroz", USP, Piracicaba - SP. 
QUADRO 3 - Concentração (ppm) e extração (mg) dos micronutricntes pelas diversas partes da planta. Média de 4 repetições.

\begin{tabular}{|c|c|c|c|c|c|c|c|c|}
\hline & & & \multicolumn{2}{|c|}{$\begin{array}{l}\text { Agosto } \\
\text { (inverno) }\end{array}$} & \multicolumn{2}{|c|}{$\begin{array}{l}\text { Novembro } \\
\text { (primavera) }\end{array}$} & \multicolumn{2}{|c|}{$\begin{array}{l}\text { Janeiro } \\
\text { (verão) }\end{array}$} \\
\hline & & & $\%$ & $\mathrm{~g}$ & $\%$ & $\mathrm{~g}$ & $\%$ & $\mathrm{~g}$ \\
\hline \multirow[t]{5}{*}{ B } & - & Folhas & 32 & 3,3 & 23 & 0,6 & 41 & 3,3 \\
\hline & & Caule & 16 & 5,8 & 16 & 0,4 & 29 & 3,5 \\
\hline & & Raízes & 13 & 5,2 & 13 & 3,1 & 29 & 5,1 \\
\hline & & Xilopódio & 15 & 1,7 & 17 & 2,8 & 39 & 2,8 \\
\hline & & Total & - & 16.0 & - & 6,9 & - & 14,7 \\
\hline \multirow[t]{5}{*}{$\mathrm{Cu}$} & - & Folhas & 9 & 0,9 & 11 & 0,3 & 4 & 0,3 \\
\hline & & Caule & 8 & 2,8 & 13 & 0,3 & 9 & 1,1 \\
\hline & & Raizes & 6 & 2,3 & 10 & 2,3 & 5 & 09 \\
\hline & & Xilopódio & 4 & 0,4 & 11 & 1,7 & 6 & 2.7 \\
\hline & & Total & - & 6,4 & - & 4,6 & - & $2, \overline{7}$ \\
\hline \multirow[t]{5}{*}{$\mathrm{Fe}$} & - & Folhas & 188 & 19,0 & 172 & 4,2 & 111 & 8,9 \\
\hline & & Caule & 261 & 91.0 & 308 & 7,5 & 178 & $21, \pi$ \\
\hline & & Raízes & 88 & 33.0 & 162 & 37,8 & 223 & 38,0 \\
\hline & & Xilopódio & 106 & 11,0 & 504 & 80,0 & 519 & 37.1 \\
\hline & & Total & - & 154,0 & - & 23,5 & - & 105,7 \\
\hline \multirow[t]{5}{*}{ Mn } & - & Folhas & 93 & 9,4 & 192 & 4,7 & 155 & 12,3 \\
\hline & & Caule & 235 & 83,0 & 435 & 106 & 207 & 25.2 \\
\hline & & Raizes & 35 & 13,7 & 97 & 22,6 & 33 & 5,6 \\
\hline & & Xilopódio & 69 & 7.4 & 127 & 20,1 & 75 & 5,4 \\
\hline & & Total & - & 113,5 & - & 58,0 & - & $48, \overline{7}$ \\
\hline \multirow[t]{5}{*}{ Mo } & - & Folhas & 0,08 & $9,0^{*}$ & 0,06 & $1,6^{*}$ & 0,04 & $3,7^{*}$ \\
\hline & & Caule & 0,06 & 22.1 & 0,04 & 1,1 & 0,07 & 9,3 \\
\hline & & Raízes & 0,09 & 37,0 & 0,05 & 12,8 & 0,03 & 6,5 \\
\hline & & Xilopódio & 0,03 & 3,4 & 0,09 & 15,3 & 0,06 & 4,3 \\
\hline & & Total & - & 71,5 & - & 30,8 & - & 23,8 \\
\hline \multirow[t]{5}{*}{$\mathrm{Zn}$} & - & Folhas & 18 & 1,8 & 25 & 0.6 & 23 & 1.2 \\
\hline & & Caule & $\therefore 3$ & 8,1 & 25 & 0,6 & 24 & 2,9 \\
\hline & & Raízes & 17 & 6.5 & 27 & 0,6 & 16 & 2.7 \\
\hline & & Xilopódio & 26 & 2,8 & 39 & 0,6 & 29 & 2,1 \\
\hline & & Total & - & 19.2 & - & 2,4 & - & 8,9 \\
\hline
\end{tabular}

* Valores para folhas, cattles, raizes, xilopódio e total expressos em mg.

para pares vicariantes (Dalbergia migra Fr. All. e D. Violacea (Vog) Malme na ordem de $1,5 \%$ no limbo das quatro folhas a partir da gema apical. Valores igualmente elevados em Ca $(2,5 \%)$, nos mesmos órgãos foram detectados para pares não vicariantes (Didymopanax vinosum March e D. Macrocarpum Sum).

A concentração de $\mathbf{S}$ nas folhas do material do presente trabalho mostram-se muito baixa em agosto, elevando-se sensivelmente, em novembro e estabilizando-se em janeiro. 
Chama a atenção o fato que as concentrações dos macronutrientes no xilopódio se mantiveram aproximadamente constantes, com excessão do $\mathrm{N}$ e $\mathrm{Ca}$. A concentração de $\mathrm{N}$ é mais elevada no verão e a do $\mathrm{Ca}$ na primavera.

$\mathrm{Na}$ quantidade total de nutrientes retirados do solo durante o ano liderou em primeiro lugar o $\mathrm{Ca}$, segundo do $\mathrm{K} ; \mathrm{N}$ em terceiro lugar; $\mathrm{Mg}$ -em quarto; $\mathrm{S}$ em quinto e $\mathrm{P}$ por último.

No quadro 3 estão assinaladas as concentrações (ppm) e extrações das estações do ano. Observa-se, que a estação do ano não influência sensivelmente sobre a concentração dos micronutrientes nas folhas, com excessão do $\mathrm{Mn}$ onde no mês de novembro ocorreu um aumento significativo.

Observa-se, ainda, quantidades maiores de $\mathrm{Cu}, \mathrm{Fe}, \mathrm{Mn}$ e $\mathrm{Mo}$ no xilopódio no mês de novembro. O B é mais acumulado no xilopódio no mês de janeiro, ao passo que para Zn a acumulação maior ocorreu nos meses de agosto e janeiro.

A extração total dos micronutrientes obedeceu a seguinte ordem decrescente: $\mathrm{Fe}, \mathrm{Mn}, \mathrm{B}, \mathrm{Zn}, \mathrm{Cu}$ e Mo.

Comparando-se os teores encontrados nas folhas das plantas do cerrado do presente trabalho com os apresentados por EPSTEIN (1972) em plantas cultivadas (quadro 4) observa-se, que os macronutrientes nas plantas nativas estavam bem próximas das encontradas em plantas cultivadas, com excessão para $\mathrm{N}$ e $\mathrm{P}$. Para os micronutrientes os valores encontrados nas plantas nativas, superaram os das plantas cultivadas, com excessão do Mo.

QUADRO 4 - Dados comparativos da concentração de nutrientes nas folhas.

\begin{tabular}{lcc}
\hline Elementos & EPSTEIN (1972) & Byrsonima coccolobifolia \\
\hline $\mathrm{N} \%$ & 1,5 & $0,09-0,96$ \\
$\mathrm{P}$ & 0,2 & $0,03-0,12$ \\
$\mathrm{~K}$ & 1,0 & $0,58-1,15$ \\
$\mathrm{Ca}$ & 0,5 & $0,55-0,58$ \\
$\mathrm{Mg}$ & 0,2 & $0,05-0,27$ \\
$\mathrm{~S}$ & 0,1 & $0,01-0,10$ \\
\hline \hline $\mathrm{B}$ ppm & 20 & $32-41$ \\
$\mathrm{Cu}$ & 6 & $4-9$ \\
$\mathrm{Fe}$ & 100 & $111-188$ \\
$\mathrm{Mn}$ & 50 & $93-192$ \\
$\mathrm{Mo}$ & 0,1 & $0,04-0,08$ \\
$\mathrm{Zn}$ & 20 & $18-25$ \\
\hline
\end{tabular}




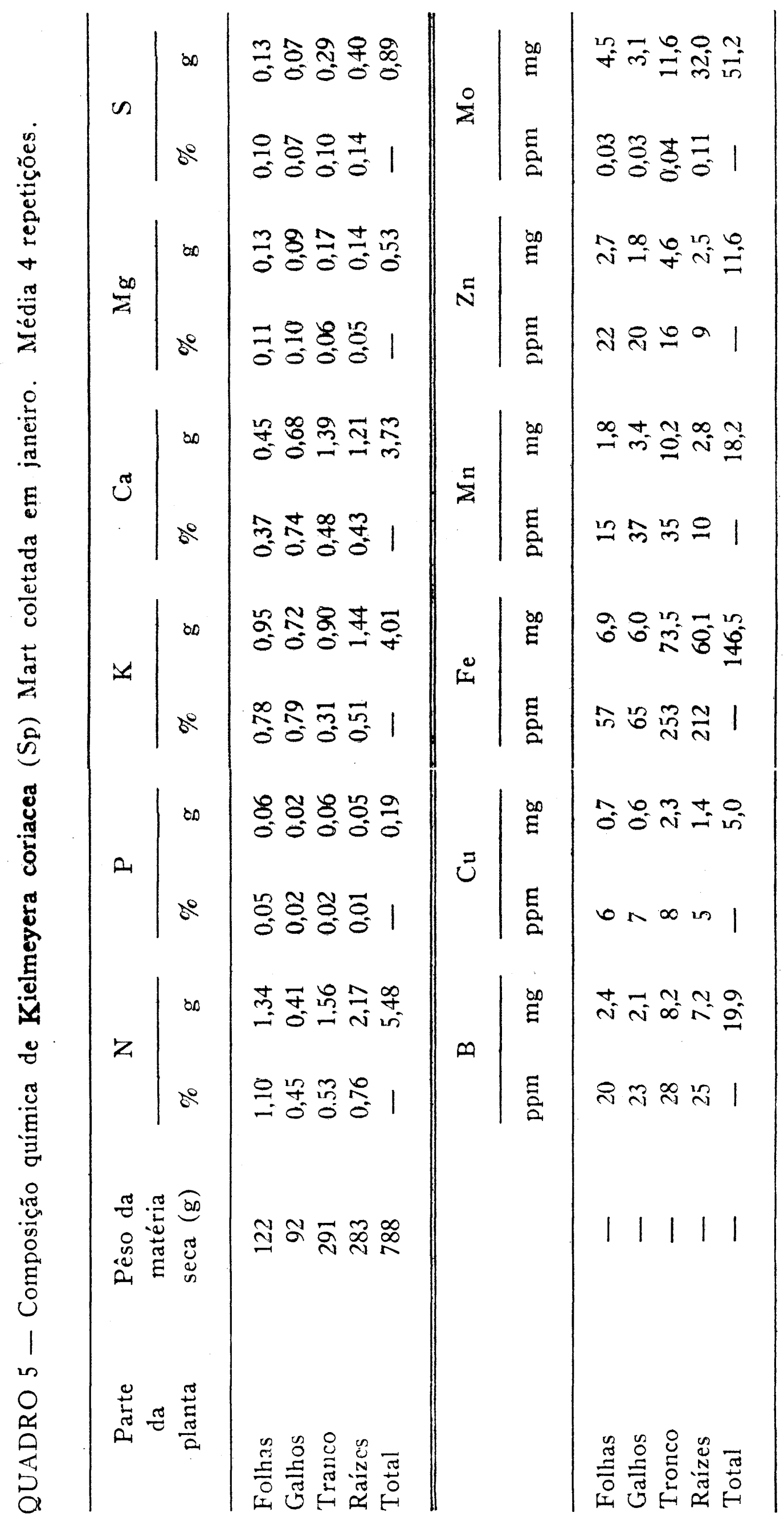




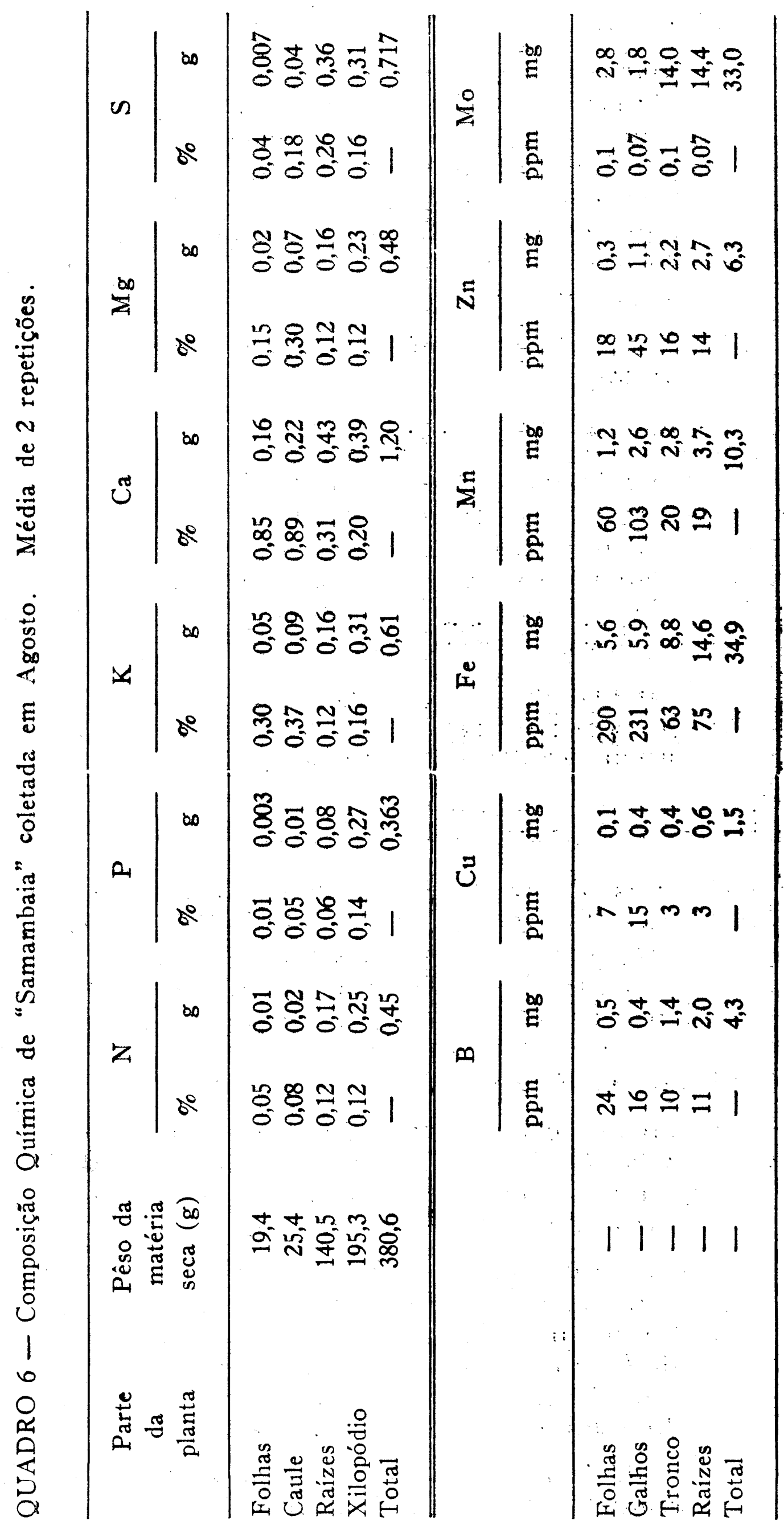


Composição Química de Kielmeyera Corriacea Mart.

O quadro 5 aponta as concentrações e quantidades de nutrientes encontradas nas plantas no mês de janeiro, na estação do verão. Comparando-se para a mesma época, com a espécie já discutida (quadros 2 e 3), observa-se que os valores encontrados foram próximos excentuando-se os de Mn. Digno de nota é o fato que ambas as espécies vegetando em um solo ácido que apresentaram elevadas quantidades de Mn disponível apresentando um mecanismo seletivo na absorção e translocação para parte aérea deste micronutriente.

A quantidade total de nutrientes do solo em ordem decrescente foi: N, K, Ca, S, Mg, P, Fe, B, Mn, Zn, Cu e Mo.

Composição Química da "Samambaia"

Os valores assinalados no quadro 6, confrontando-se estes valores com os apresentados nas plantas cultivadas (quadro 4) observa-se, que a concentração nos macronutrientes nas folhas inferior com excessão do $\mathrm{Ca}$, que foi o elemento extraído em maiores quantidades pela planta. A extração total dos macronutrientes obedecem a seguinte ordem decrescecente: $\mathrm{Ca}, \mathbf{S}, \mathbf{K}, \mathbf{M g}, \mathbf{N}$ e $\mathbf{P}$ :

A concentração dos micronutrientes nas folhas foi na mesma ordem de grandeza das plantas cultivadas e a extração total pela "samambaia" foi na seguinte ordem decrescente: $\mathrm{Fe}, \mathrm{Mn}, \mathrm{Zn}, \mathrm{B}, \mathrm{Cu}$ e finalmente o Mo.

\section{Concentração de Al nas Espécies:}

O quadro 7 apresenta as concentrações e extração de $\mathrm{Al}$ nas diversas partes das espécies. De acôrdo com CHENERY (1949) citado por GOODLAND (1971), para que uma planta possa ser chamada acumuladora de $\mathrm{Al}$ é necessário que apresente concentração igual ou superior a $1.000 \mathrm{ppm}$ na matéria seca. Valores em torno de $200 \mathrm{ppm}$ são considerados teores "regulares". Neste sentido as espécies analisadas não são consideradas como plantas acumuladoras de Al.

Pelo exame do quadro 6 observa-se que a concentração de Al na Byrsonima coccolobifolia é mais elevada no verão nas folhas e em especial no xilopódio; sendo que no mês de novembro, primavera, os valores foram inferiores as duas estações do ano.

Interessante observar que na espécie Kilmeyera coriacea os ions de Al foram bem mais baixos, especialmente nas folhas e nos galhos. $\mathrm{Na}$ "samambaia" é chamada a atenção para os valores intermediários na concentração de Al em confronto com as duas espécies já comentadas. Chama a atenção ainda, a baixa concentração de Al no xilopódio, indicando uma translocação de Al, para a parte aérea do vegetal.

A acumulação de $\mathrm{Al}$ foi maior na Byrsonima coccolobifolia seguida da Kielmeyera coriacea e em quantidade bem menor na "samambaia". 


\section{CONCLUSÕES}

Para Byrsonima coccolobifolia (Sp) Kunth

1 - A produção de matéria seca não acompanha as estações climáticas;

2 - Teores dos macronutrientes, nas folhas assemelham-se com os das plantas cultivadas, com excessão de $N$ e $P$, que são inferiores;

3 - Teores dos micronutrientes, nas folhas, são superiores aos das plantas cultivadas, com excessão do Mo que se apresenta em concentração inferior;

4 - O xilopódio não armazena nutrientes;

5 - A espécie não é acumuladora de Al.

QUADRO 7 - Concentração (ppm) e extração $(\mathrm{mg})$ ou Al pelas diversas partes das espécies coletadas. Média de 4 repetições.

\begin{tabular}{|c|c|c|c|c|c|c|c|}
\hline \multirow[t]{2}{*}{ Espécies } & \multirow{2}{*}{$\begin{array}{c}\text { Partes } \\
\text { da } \\
\text { planta }\end{array}$} & \multicolumn{2}{|c|}{ Agosto } & \multicolumn{2}{|c|}{ Novembro } & \multicolumn{2}{|c|}{ Janeiro } \\
\hline & & ppm & $\mathrm{mg}$ & $\mathrm{ppm}$ & $\mathrm{mg}$ & ppm & $\mathrm{mg}$ \\
\hline \multirow{5}{*}{$\begin{array}{l}\text { Byrsonima } \\
\text { coccolobifolia }\end{array}$} & Folhas & 135 & 13,6 & 125 & 3,1 & 236 & 18,9 \\
\hline & Caule & 145 & 51,0 & 250 & 6,1 & 309 & 37,6 \\
\hline & Raízes & 177 & 67,5 & 80 & 18,7 & 441 & 75,9 \\
\hline & Xilopódio & 277 & 29.9 & 286 & 45,4 & 437 & 31,2 \\
\hline & Total & - & 162,0 & - & 73,3 & - & 163,6 \\
\hline \multirow{5}{*}{$\begin{array}{r}\text { Kielmeyera } \\
\text { coriacea }\end{array}$} & Folhas & - & - & - & - & 70 & 8,5 \\
\hline & Galhos & - & - & - & - & 68 & 6,2 \\
\hline & Tronco & - & - & - & - & 159 & 46,2 \\
\hline & Raízes & - & - & - & - & 275 & 78,0 \\
\hline & Total & - & - & - & - & - & 138,9 \\
\hline \multirow[t]{5}{*}{ "Samambaia" } & Folhas & - & - & - & - & 176 & 3,4 \\
\hline & Galhos & - & - & - & - & 186 & 4,7 \\
\hline & Tronco & - & - & - & - & 99 & 13,9 \\
\hline & Raízes & - & - & - & - & 57 & 11,1 \\
\hline & Total & - & - & - & - & - & 33,1 \\
\hline
\end{tabular}

Para Kielmeyera coriacea.

1 - Teores dos macronutrientes, nas folhas em janeiro são inferiores aos das plantas cultivadas, com excessão do Ca que são superiores;

2 - Teores dos micronutrientes nas folhas em janeiro, são da mesma ordem de grandeza encontradas nas plantas cultivadas;

3 - O xilopódio aramzena macro e micronutrientes;

4 - A "samambaia" não é acumuladora de Al. 


\section{SUMMARY}

\section{MINERAL NUTRITION OF CERRADO SPECIES I. INORGANIC CHEMICAL COMPOSITION OF Byrsonima coccolobifolia (Sp) KUNTH, Kielmeyera coriacea (Sp) MART AND "SHURB" (Polypodiaceae)}

The word "Cerrado" is used in Brazil in a broad sense. In the wide sense, it is a regional large-scale vegetation type that forms both a vegetational and a floristic province.

This large-scale vegetational province posseses a distinctive flora with a few endemic genera and hundreds of endemic species.

In the present work, the authors, run analysis of the differents parts of three species collected during one year, from a Regosol (Entisols), situated at the region of Cajurú, São Paulo, Brazil. In this paper, analysis of $\mathrm{N}, \mathrm{P}, \mathrm{K}, \mathrm{Ca}, \mathrm{Mg}, \mathrm{S}, \mathrm{B}, \mathrm{Cu}, \mathrm{Fe}, \mathrm{Mn}$, $\mathrm{Mo}, \mathrm{Zn}$ and $\mathrm{Al}$ are presented.

From the data the followings conclusions may be draw:

1 - The year seasons does not affected markedly the dry matter production of the species;

2 - The concentration on macro and micronutrients, with few exceptions, are similars to the cultivated plants;

3 - The lignotuber of "shrub" plant actually accumulate nutrients;

4 - All of the studied species are not aluminium accumulator plants.

\section{LITERATURA CITADA}

BLANCO, H.C., H. GODOY, 1967. Carta das chuvas do Estado de São Paulo. Secretaria da Agricultura do Estado de São Paulo. Instituto Agronômico de Campinas

COMISSÃO DE SOLOS, 1960. Levantamento de reconhecimento dos solos do Estado de São Paulo. Ministro da Agricultura, Centro Nacional de Pesquisas Agronômica Boletim N..$^{\circ}$ 12.634 p. Rio de Janeiro.

CERVELLINI, A; E. SALATI, 1966. Estimativa da distribuição da energia solar no Estado de São Paulo - Bragantia 25:31-39.

EMBRAPA, 1976. CERRADO - Bibliografia Análitica. EMBRAPA Brasília.

EPSTEIN, E. 1972. Mineral Nutrition of Plants: Principles and Perspectives John Wiley \& Sons Mc. 412 p. New York.

FERRI, M.G., 1969. Plantas do Brasil Espécies do Cerrado Ed. Edgard Blücher 239 p. São Paulo.

GOODLAND, R., 1971. Aligotrofismo e alumínio no cerrado p. 44 In III Simpósio sobre Cerrado. Ed. da Univ. de São Paulo e Ed. Edgard Blücher. 239 p. São Paulo.

GOTTLIEB, O.R., J. de O. MEDITSH, M.T. MAGALHÃES, 1966. Com vistas ao aproveitamento do Cerrado como Ambiente Natural: Composição Química de Espécies Orbóreas - 1966. On Acard. Bras. Ci. 38 (supl): 303-314.

LABOURIAU, L.G., 1966. Revisão da Situação da Ecologia Vegetal nos Cerrados. An. Acad. Bras. Ci. 38 (supl.): 5-38.

MEDITSH, J. de O., 1966a. Teor de alguns constituintes inorgânicos no ráquis e limbo das folhas de vegetais do Cerrado. Eng. e Química 18 5-7.

MEDITSH, J. de O., 1966. Fósforo em pares vicariantes, não vicariantes e em vegetais do cerrado. Eng. e Química - 18: 10-14.

SARRUGE, J.R., H.P. HAAG, 1974. Análise química em plantas E.S.A. “Luiz de Queiroz" - 56 p. - Piracicaba, SP. 